\title{
MicroRNA-708-5p affects proliferation and invasion of osteosarcoma cells by targeting URGCP
}

\author{
CONG SUI $^{1 *}$, DEBAO LIU ${ }^{1 *}$, YONG HU $^{1}$ and LINLIN ZHANG ${ }^{2}$ \\ ${ }^{1}$ Department of Orthopedics, The First Affiliated Hospital of Anhui Medical University, Hefei, Anhui 230032; \\ ${ }^{2}$ Department of Orthopaedics, The First Affiliated Hospital of University of Science and Technology of China, \\ Hefei, Anhui 230001, P.R. China
}

Received March 9, 2018; Accepted November 26, 2018

DOI: $10.3892 /$ etm.2019.7171

\begin{abstract}
Osteosarcoma is an aggressive cancer of the skeletal system which remains a challenge for the current therapeutic strategies due to unclear etiology and molecular mechanisms of pathogenesis. The current study aimed to determine the expression levels, role and molecular mechanism of microRNA-708-5p (miR-708-5p) in the development of osteosarcoma. The expression level of miR-708-5p was detected using reverse transcription-quantitative polymerase chain reaction. miR-708-5p was overexpressed in SaOS-2 cells using miR-708-5p mimics. Cell viability, apoptosis, migration and invasion were determined using Cell Counting kit- 8 assay, flow cytometry, wound healing and transwell assays, respectively. The results indicated that miR-708-5p was significantly downregulated in osteosarcoma tissues and cells, and its overexpression significantly inhibited cell viability, invasion and migration and induced apoptosis of SaOS-2 cells. Furthermore, the present results indicated that miR-708-5p directly targeted the 3'-untranslated region of up-regulator of cell proliferation (URGCP) and negatively regulated its expression in SaOS-2 cells. Taken together, the current study suggested that miR-708-5p may inhibit the growth and invasion of osteosarcoma cells via regulating the URGCP/NF- $\mathrm{B}$ signaling pathway. Further research on these molecules in osteosarcoma may provide novel insights into the target therapy for this disease.
\end{abstract}

\section{Introduction}

Osteosarcoma is the most common primary malignant bone tumor with the highest incidence among patients aged

Correspondence to: Dr Yong Hu, Department of Orthopedics, The First Affiliated Hospital of Anhui Medical University, 218 Jixi Road, Hefei, Anhui 230032, P.R. China

E-mail: huyong201802@163.com

\section{${ }^{*}$ Contributed equally}

Key words: osteosarcoma, miR-708-5p, up-regulator of cell proliferation, proliferation, metastasis
10-20 years $(1,2)$. The annual incidence of osteosarcoma is five per million. Since, in $80 \%$ of patients with osteosarcoma, metastasis or micrometastasis has occurred at the time of diagnosis, almost all patients receive multiple doses of chemotherapy in addition to surgery (3). Recent improvements in surgical methods resulted in decreased numbers of amputations among patients with osteosarcoma (4). The understanding of molecular mechanisms of osteosarcoma may contribute to the development of targeted therapy for this disease (5). Development of novel treatment strategies and improvement of the currently available methods may increase the survival rate of patients with osteosarcoma.

In recent years, numerous studies have demonstrated that microRNAs (miRNAs) serve important regulatory roles in tumor formation and progression (6-9). A number of oncogenes and tumor suppressor genes are regulated by miRNAs (10). miRNAs are single-stranded, non-coding RNAs that recognize specific target mRNAs and regulate the expression of target genes at the post-transcriptional level (11-13). miRNAs promote the degradation of mRNA and/or inhibit the translation process, and regulate the translation of $\sim 30 \%$ of the protein-coding mRNA in the human genome (11-13). Previous studies indicated that the expression of miRNAs is abnormal in numerous types of tumors (6-9). miRNAs may serve carcinogenic or tumor suppressive roles by regulating downstream target genes and influencing the biological behavior of tumor cells, including proliferation, apoptosis, invasion, metastasis and angiogenesis (14). The majority of tumor suppressor miRNAs are downregulated in malignant cells, while oncogenic miRNAs are upregulated and affect tumor pathology through multiple mechanisms $(15,16)$.

miR-708-5p is a miRNA expressed in a number of diseases (17). miR-708-5p was first identified in normal tissues and tumor samples from patients with cervical cancer, and exhibits a high degree of sequence similarity with miR-28 $(18,19)$. The passenger strand of miR-708 (miR-708-3p) shows potential biological function and is incorporated into the RNA-induced silencing complex (20-25). miR-708-5p is involved in numerous diseases, including cancer, neurodegenerative diseases and cardiovascular diseases (26-30).

The current study aimed to determine the role of miR-708-5p in the occurrence and development of osteosarcoma. This miRNA may become a clinical marker for the diagnosis of this 
type of cancer and the results of the current study may provide theoretical basis for diagnosis and treatment.

\section{Materials and methods}

Clinical specimens. Osteosarcoma tissue and adjacent normal tissue samples were obtained from 60 patients (age, 14-65 years; 32 males and 28 females; 9 cases without tumor metastasis; 23 cases with lymph node metastasis without distant metastasis; 28 cases with distant metastasis) diagnosed with osteosarcoma by pathological examination between May 2011 and May 2016 at the First Affiliated Hospital of Anhui Medical University and The First Affiliated Hospital of University of Science and Technology of China (Hefei, China). Patients were included in the present study if they did not receive radiotherapy or chemotherapy, and exhibited normal cardiopulmonary, liver and kidney function. Patients with chronic conditions including high blood pressure, chronic heart disease and kidney failure were excluded. All experiments involving human tissues were reviewed and approved by the Ethics Committee of the First Affiliated Hospital of Anhui Medical University and by the Ethics Committee of the First Affiliated Hospital of University of Science and Technology of China. All patients provided written informed consent for the use of their tissues.

Cell culture and treatment. Human osteosarcoma cell line SaOS-2 and normal osteoblast cell line hFOB1.19 were purchased from American Type Culture Collection (Manassas, VA, USA) and cultured in the First Affiliated Hospital of Anhui Medical University. Cells were grown in RPMI 1640 medium containing $10 \%$ fetal bovine serum (FBS; both Gibco; Thermo Fisher Scientific, Inc., Waltham, MA, USA) and $1 \%$ penicillin-streptomycin solution (Sigma-Aldrich; Merck KGaA, Darmstadt, Germany), and incubated at $37^{\circ} \mathrm{C}$ with $5 \% \mathrm{CO}_{2}$. Cells were passaged every 2-3 days.

SaOS- 2 cells $\left(3 \times 10^{4}\right.$ cells/well) were transiently transfected with 100 nM miRNA-708-5p mimics (AAGGAGCUUACA AUCUAGCUGGG and CAGCUAGAUUGUAAGCUCCUU UU), negative control mimics (UUCUCCGAACGUGUCACG UTT and ACGUGACACGUUCGGAGAATT), miR-708-5p inhibitors (CCCAGCUAGAUUGUAAGCUCCUU) or negative control inhibitors (CAGUACUUUUGUGUAGUACAA) using Lipofectamine ${ }^{\circledR} 2000$ (Invitrogen; Thermo Fisher Scientific, Inc.) according to the manufacturer's protocol. The miR-708-5p mimics, miR-708-5p inhibitor and negative controls were purchased from Shanghai GenePharma Co., Ltd. (Shanghai, China). After $48 \mathrm{~h}$, reverse transcription-quantitative polymerase chain reaction (RT-qPCR) was used to determine transfection efficiency, as described below. Cells without any treatment were used as the control group.

Western blot analysis. Following treatment, total cellular proteins from SaOS-2 cells were extracted using radioimmunoprecipitation assay buffer (Hunan Auragene Biotech Co., Ltd, Changsha, China). Bicinchoninic acid protein quantification kit (Thermo Fisher Scientific, Inc.) was used to measure the protein concentration in samples. Equal amounts of protein ( $30 \mu \mathrm{g} /$ lane) were resolved by SDS-PAGE on a $12 \%$ gel and transferred onto polyvinylidene fluoride membranes.
The membranes were blocked with $5 \%$ non-fat milk at room temperature for $1 \mathrm{~h}$, followed by incubation with primary antibodies, including anti-up-regulator of cell proliferation (URGCP; cat. no. ab103323; 1:1,000; Abcam, Cambridge, MA, USA), anti-nuclear factor (NF)- $\mathrm{B}$ (cat no. 8242) and anti-GAPDH (cat. no. 8884; both 1:1,000; Cell Signaling Technology, Inc., Danvers, MA, USA) at $4{ }^{\circ} \mathrm{C}$ overnight. Subsequently, the membranes were incubated with an anti-rabbit immunoglobulin $\mathrm{G}$ horseradish peroxidase-conjugated secondary antibody (cat. no. 7074; 1:2,000; Cell Signaling Technology, Inc.) at room temperature for $2 \mathrm{~h}$. To visualize the protein blots, the enhanced chemiluminescence Western Blotting Detection kit (Applygen Technologies, Inc., Beijing, China) was used according the manufacturer's protocol.

$R T$-qPCR. TRIzol reagent (Invitrogen; Thermo Fisher Scientific, Inc.) was used to extract total RNA from cells and tissues. GAPDH or U6 were used as internal controls for mRNA or miRNA expression, respectively. cDNA was synthesized using PrimeScript ${ }^{\mathrm{TM}}$ RT reagent kit (Takara Bio, Inc., Otsu, Japan) according to the manufacturer's protocol. SYBR $^{\circledR}$ Premix Ex Taq ${ }^{\mathrm{TM}}$ (Takara Bio, Inc.) was used for qPCR according to the manufacturer's protocol. The following primer sequences were used for the qPCR: miR-708-5p, forward 5'-GGCGCGCAAGGAGCTTACAATC-3' and reverse 5'-GTGCAGGGTCCGAGGTAT-3'; URGCP, forward: 5'-CTTCATCCTGAGTCCCTACCG-3' and reverse: 5'-GCC GTTCTGCTGCATTCG-3'; NF- $\mathrm{B}$, forward: 5'-AACACT GCCGACCTCAAGAT-3' and reverse: 5'-CATCGGCTTGAG AAAAGGAG-3'; U6, forward 5'-GCTTCGGCAGCACAT ATACTAAAAT-3' and reverse 5'-CGCTTCACGAATTTG CGTGTCAT-3'; and GAPDH, forward 5'-CTTTGGTATCGT GGAAGGACTC-3' and reverse 5'-GTAGAGGCAGGGATG ATGTTCT-3'. Relative expression of each gene was calculated using the $2^{-\Delta \Delta \mathrm{Cq}}$ method (31).

Cell migration and invasion assays. An in vitro invasion assay was performed using transwell plates (BD Biosciences, Franklin Lakes, NJ, USA) with $8 \mu \mathrm{m}$ pores. Chamber inserts were coated with $200 \mathrm{mg} / \mathrm{ml}$ BD Matrigel ${ }^{\mathrm{TM}}$ matrix (BD Biosciences) at room temperature overnight. The SaOS- 2 cells $\left(1 \times 10^{4}\right.$ cells $)$ in RPMI 1640 medium were added to the upper chamber of the transwell plates. RPMI 1640 medium containing 20\% FBS as a chemoattractant was added to the lower chamber. After a 48-h incubation, cells were removed from the upper surface using cotton swabs and the invasive cells were fixed with methanol and stained with $0.5 \%$ crystal violet at room temperature for $30 \mathrm{~min}$. Images were captured and the cells were counted using a light photomicroscope (Olympus Corporation, Tokyo, Japan) at a magnification of $\mathrm{x} 200$.

For the wound healing assay, confluent monolayers of SaOS-2 cells cultured in 24-well plates were scratched using a $10-\mu 1$ pipette tip. The wells were washed to remove cellular debris and the cells were allowed to migrate for $48 \mathrm{~h}$. Representative images were captured under an light inverted microscope (Olympus Corporation; magnification, x100). The experiments were repeated at least three times.

Cell Counting Kit-8 (CCK-8) assay. SaOS-2 cells were seeded into a 96 -well plate $\left(2 \times 10^{5}\right.$ cells/well $)$ and cultured in 

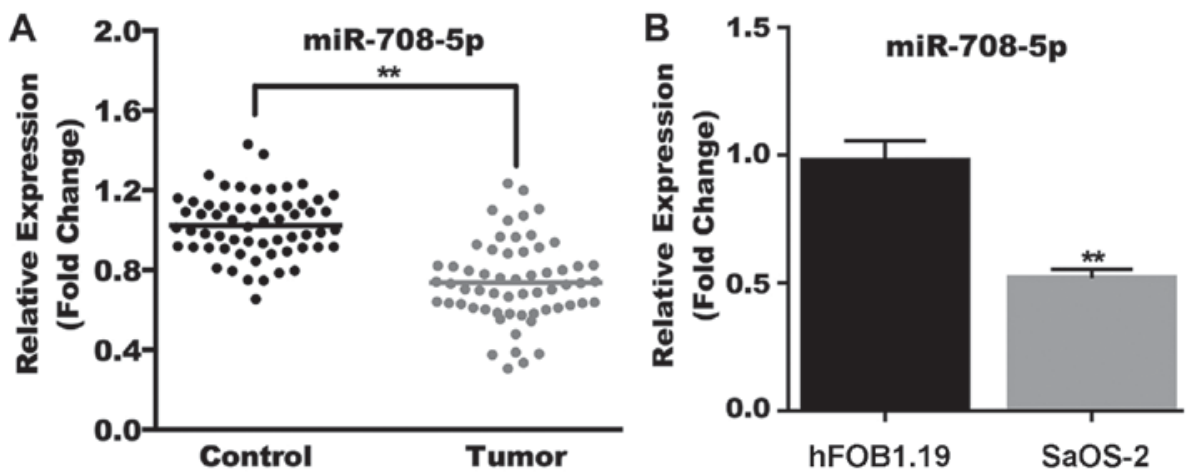

Figure 1. miR-708-5p expression in osteosarcoma. (A) The expression level of miR-708-5p was detected in osteosarcoma tissues and the adjacent normal tissues. ${ }^{* *} \mathrm{P}<0.01$ vs. control. (B) miR-708-5p expression was determined in osteosarcoma cell line SaOS-2 and normal osteoblast cell line hFOB1.19. Data are presented as the mean \pm standard deviation. ${ }^{* *} \mathrm{P}<0.01$ vs. hFOB1.19. Tumor, osteosarcoma tissues; control, adjacent normal tissues; miR, microRNA.
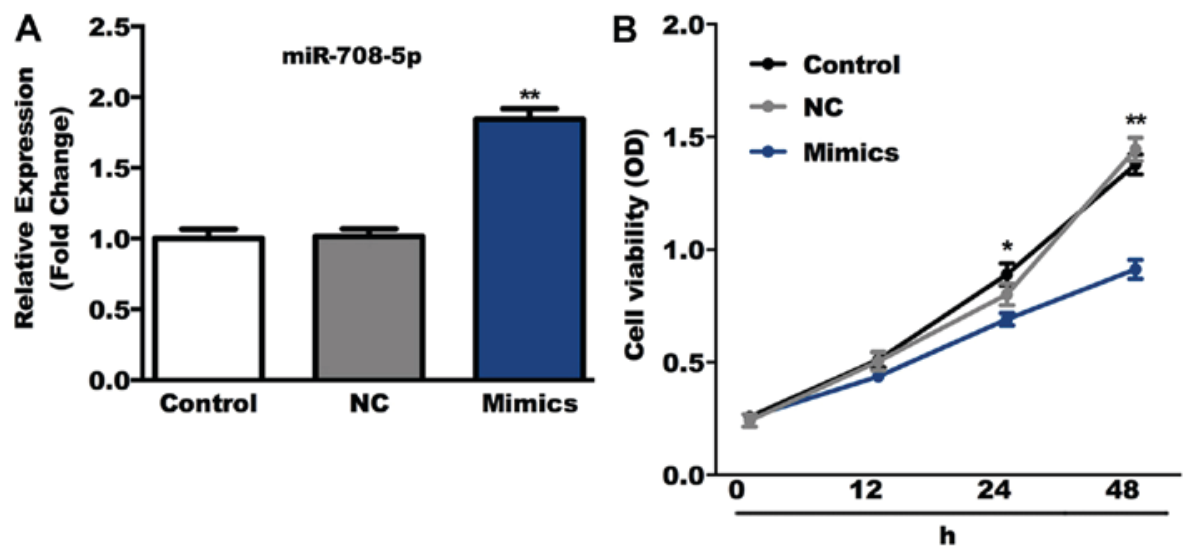

Figure 2. miR-708-5p inhibits SaOS-2 cell viability. (A) Expression level of miR-708-5p in SaOS-2 cells from different groups was detected using reverse transcription-quantitative polymerase chain reaction. ${ }^{* *} \mathrm{P}<0.01$ vs. the control group. (B) Cell viability was measured using the Cell Counting Kit- 8 assay. ${ }^{*} \mathrm{P}<0.05$ and $^{* *} \mathrm{P}<0.01$ vs. mimics. Data are presented as the mean \pm standard deviation. NC, negative control; miR, microRNA; OD, optical density.

RPMI-1640 medium at $37^{\circ} \mathrm{C}$ for 24,48 and $72 \mathrm{~h}$ respectively. Cell viability was detected using the CCK-8 kit according to the manufacturer's protocol. The absorbance was measured at a wavelength of $450 \mathrm{~nm}$ using an iMark ${ }^{\circledR}$ microplate absorbance reader (Bio-Rad Laboratories, Inc., Hercules, CA, USA). The experiments were repeated at least 3 times.

Cell apoptosis detection. Following transfection, SaOS-2 cells in the logarithmic growth phase were collected and washed at least three times with cold PBS. Annexin V-FITC Early Apoptosis Detection kit (cat. no. 6592; Cell Signaling Technology, Inc.) was used for cell apoptosis analysis. In brief, SaOS-2 cells $\left(1 \times 10^{6}\right)$ from different groups were re-suspended in binding buffer, labeled with $1 \mu \mathrm{l}$ Annexin V-fluorescein isothiocyanate (FITC) and $12.5 \mu \mathrm{l}$ propidium iodide (PI) and then incubated for 10 min on ice in the dark. A flow cytometer (FACSCalibur ${ }^{\mathrm{TM}}$; BD Biosciences, Franklin Lakes, NJ, USA) was used to analyze cell apoptosis. Data were analyzed using WinMDI software (version 2.5; Purdue University Cytometry Laboratories, West Lafayette, IN, USA). The experiments were repeated at least 3 times.

Bioinformatics prediction and dual-luciferase reporter assay. Targetscan (version 7.1; www.targetscan.org/vert_71) was used to predict the putative target genes of miR-708-5p. To confirm whether miR-708-5p directly targets URGCP, a luciferase reporter assay was performed using a pEZX-MT01 target reporter plasmid containing the URGCP 3'-untranslated region (UTR; GeneCopoeia, Inc., Rockville, MD, USA). Additionally, a mutant (MUT) URGCP 3'-UTR reporter construct was generated by site-directed mutagenesis in the putative target site of miR-708-5p in the wild-type (WT) URGCP 3'-UTR using the QuikChange XL site-directed mutagenesis kit (Agilent Technologies, Inc., Santa Clara, CA, USA). The reporter plasmids were co-transfected into SaOS-2 cells with miR-708-5p mimics or the NC using Lipofectamine $3000^{\circledR}$ (Invitrogen; Thermo Fisher Scientific, Inc.) in 24-well plates. A total of $48 \mathrm{~h}$ following transfection, dual-luciferase reporter assay system (Promega Corporation, Madison, WI, USA) was used to measure luciferase activity according to the manufacturer's protocol. Relative luciferase activity was normalized to the Renilla luciferase activity. The results were obtained from three independent experiments.

Statistical analysis. All data are presented as the mean \pm standard deviation. SPSS software (version 17.0; SPSS, Inc., Chicago, IL, USA) was used for statistical analyses. Comparisons between groups were performed using Student's 

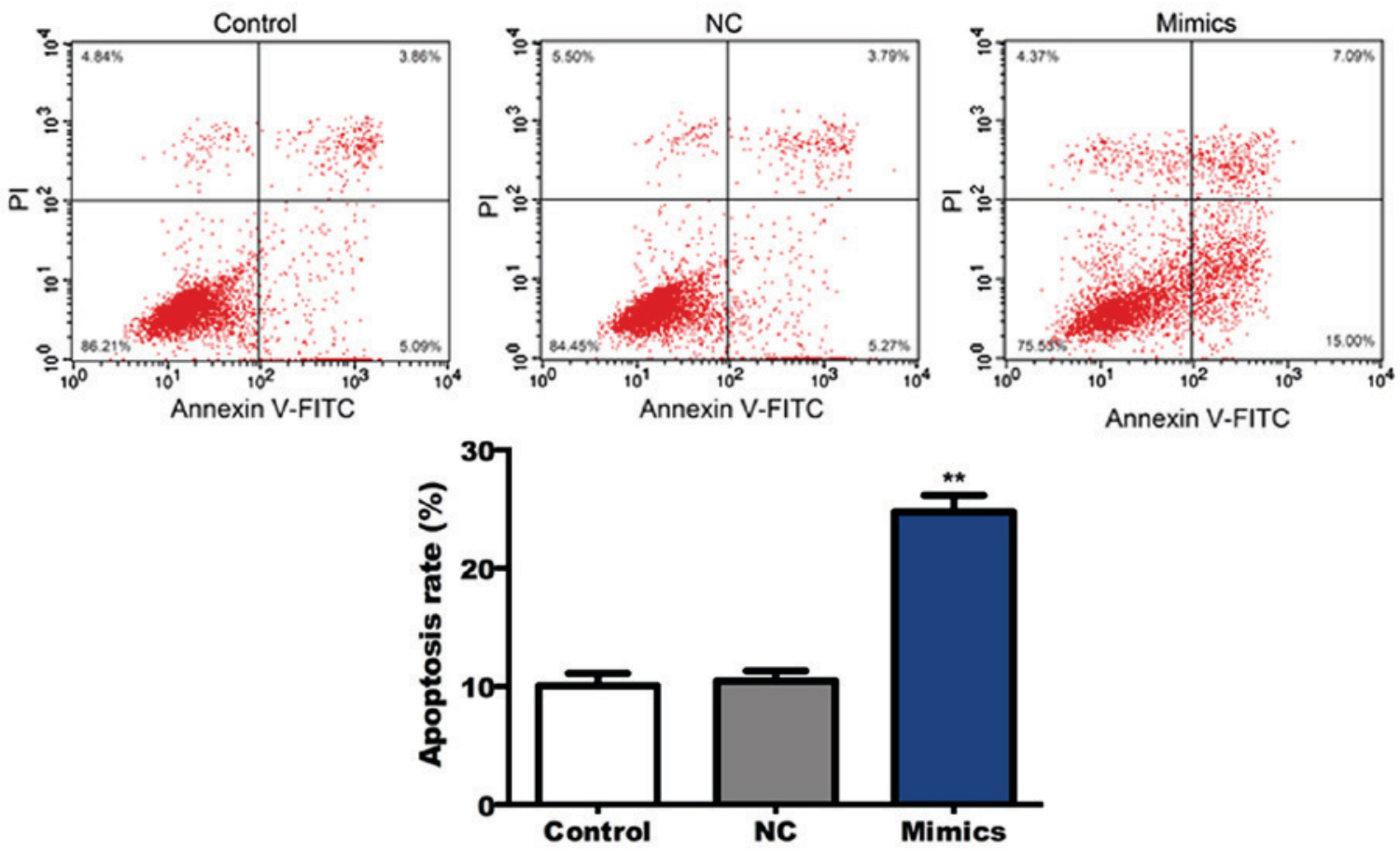

Figure 3. MicroRNA-708-5p induces SaOS-2 cell apoptosis. Following transfection, cell apoptosis was determined using flow cytometry. Data are presented as the mean \pm standard deviation. ${ }^{* *} \mathrm{P}<0.01$ vs. the control group. $\mathrm{NC}$, negative control; FITC, fluorescein isothiocyanate.

A

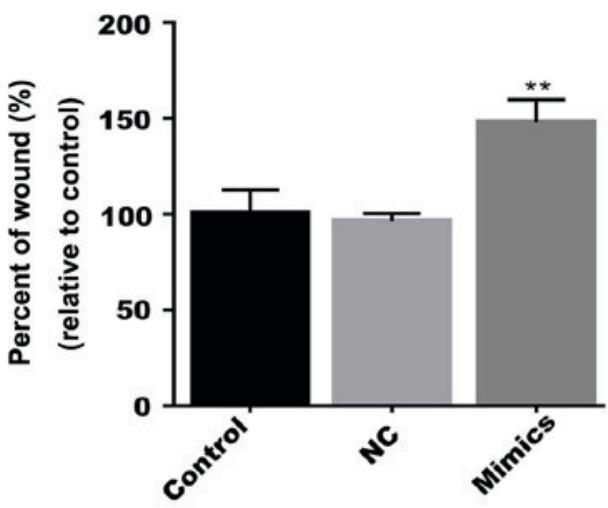

B

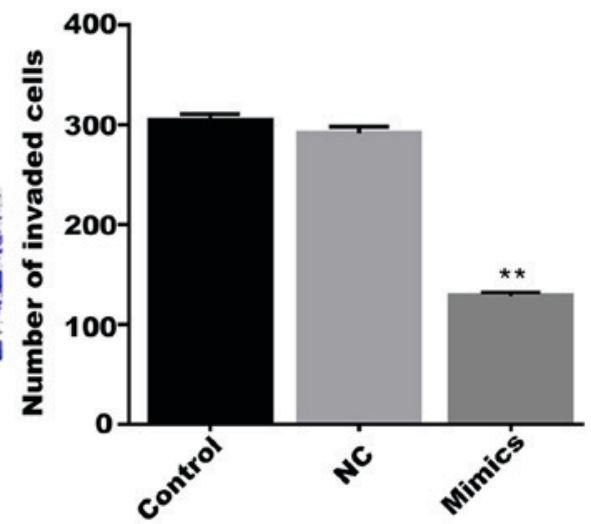

Figure 4. microRNA-708-5p inhibits SaOS-2 cell migration and invasion. Following transfection, SaOS-2 cell (A) migration was detected using wound healing assays and (B) invasion ability was detected using transwell assays, and the data were quantitatively analyzed. Magnification, $\times 200$. Data are presented as the mean \pm standard deviation. ${ }^{* *} \mathrm{P}<0.01$ vs. the control group. $\mathrm{NC}$, negative control.

t-test or one-way analysis of variance followed by Tukey's test. $\mathrm{P}<0.05$ was considered to indicate a statistically significant difference.

\section{Results}

Expression of miR-708-5p in osteosarcoma. The expression 
A

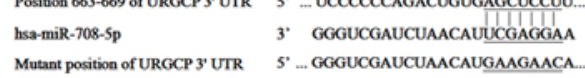

B

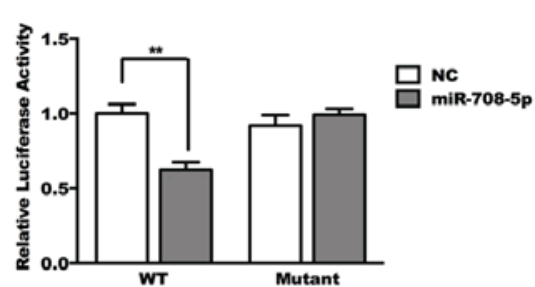

E

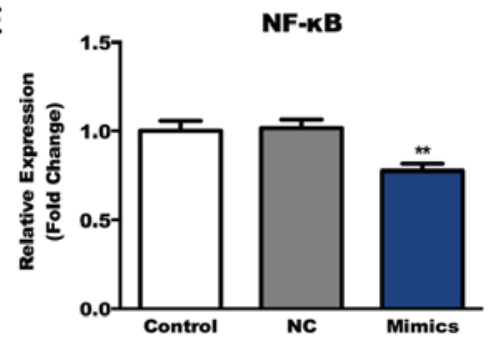

H

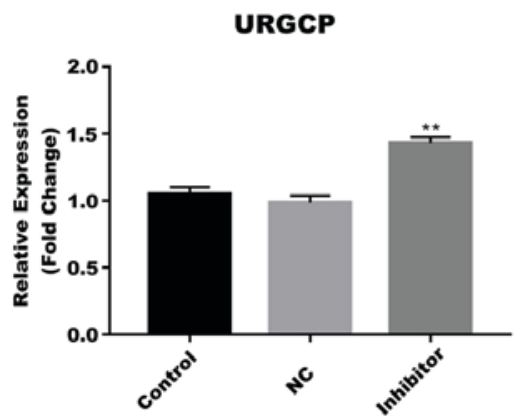

C

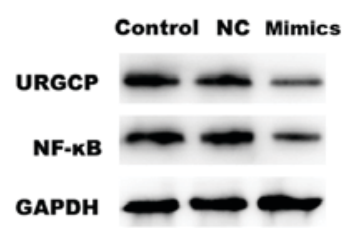

$\mathbf{F}$

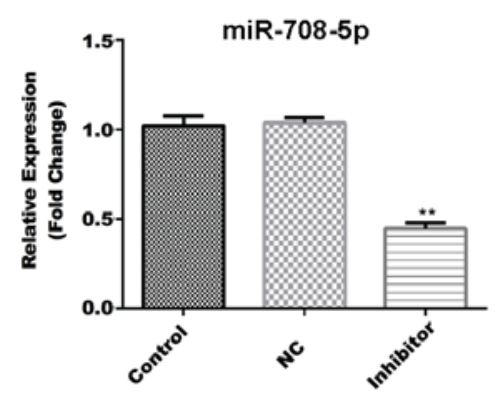

I

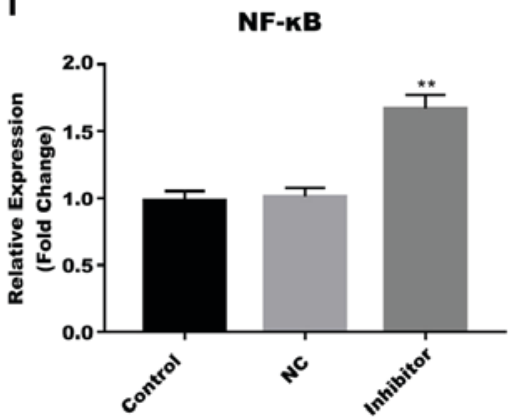

D

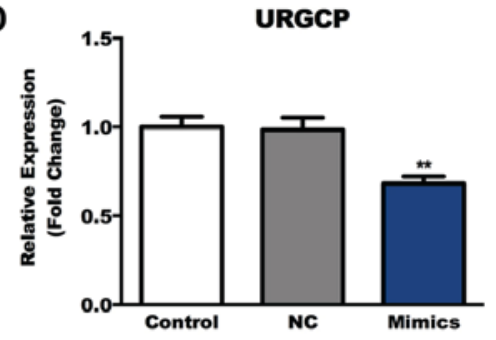

G

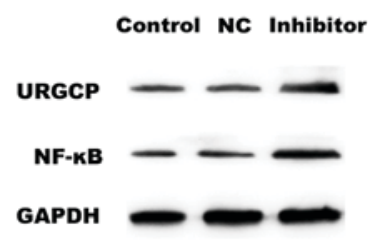

Figure 5. miR-708-5p directly targets URGCP. (A) TargetScan was used to predict the interactions between miR-708-5p and the WT 3'-UTR of URGCP. (B) Relative luciferase activity was detected by a dual-luciferase assay. ${ }^{* *} \mathrm{P}<0.01$ vs. NC. After a $48 \mathrm{~h}$ transfection with NC and miR-708-5p mimics, (C) the

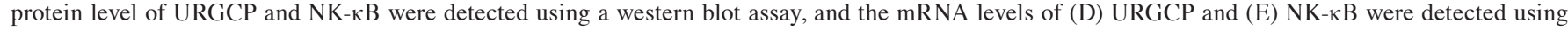
RT-qPCR. (F) miR-708-5p levels were detected after a $48 \mathrm{~h}$ transfection with NC and a miR-708-5p inhibitor using RT-qPCR. After a $48 \mathrm{~h}$ transfection with NC and a miR-708-5p inhibitor, (G) the protein level of URGCP and NK-кB were detected using a western blot assay, and the mRNA levels of (H) URGCP and (I) NK-kB were detected using RT-qPCR. Data are presented as the mean \pm standard deviation. ${ }^{* *} \mathrm{P}<0.01$ vs. the control group. miR, microRNA; URGCP,

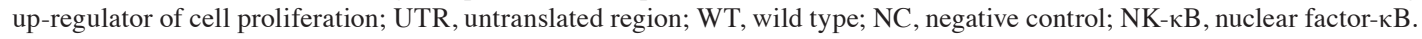

levels of miR-708-5p were detected in osteosarcoma tissues, adjacent normal tissues, human osteosarcoma cell line SaOS-2 and normal osteoblast cell line hFOB1.19 using RT-qPCR. The results indicated that compared with the adjacent normal tissues, the level of miR-708-5p in osteosarcoma tissues significantly decreased (Fig. 1A). Furthermore, the level of miR-708-5p in SaOS-2 cells was significantly lower compared with the hFOB1.19 cells (Fig. 1B).

miR-708-5p suppresses SaOS-2 cell viability and induces cell apoptosis in vitro. The role of miR-708-5p overexpression was determined in SaOS-2 cells in the present study. Cells were transiently transfected with miR-708-5p mimics or NC. RT-qPCR results confirmed that compared with the control group, the level of miR-708-5p was significantly increased in the miR-708-5p mimics group (Fig. 2A). Cell viability was subsequently detected using the CCK- 8 assay and the results indicated that, compared with the control group, miR-708-5p mimics significantly suppressed $\mathrm{SaOS}-2$ cell viability (Fig. 2B). Furthermore, SaOS-2 cell apoptosis was detected
$48 \mathrm{~h}$ following transfection with miR-708-5p mimics or NC. Flow cytometry analysis indicated that cell apoptosis significantly increased in SaOS-2 cells transfected with miR-708-5p mimics compared with the cells from the control group (Fig. 3).

miR-708-5p suppresses SaOS-2 cell migration and invasion. Cell migration and invasion were measured in the present study. A total of $48 \mathrm{~h}$ after cell transfection, wound healing and transwell assays were used to detect cell migration and invasion respectively. The results demonstrated that both migration and invasion of SaOS-2 cells in the miR-708-5p mimics group were significantly inhibited compared with the control group (Fig. 4).

miR-708-5p directly targets URGCP. Subsequent experiments were performed to determine the underlying mechanism of the effect of miR-708-5p on SaOS-2 cells. The potential targets of miR-708-5p were predicted using TargetScan. URGCP was identified as a potential target gene of miR-708-5p. To verify the binding site, the 3'-UTR of URGCP containing a WT or MUT 
sequence was cloned into $\mathrm{SaOS}-2$ cells for a subsequent firefly luciferase reporter assay. The results indicated that URGCP was a direct target gene of miR-708-5p (Fig. 5A and B). To determine the effect of miR-708-5p on the URGCP signaling pathway, cells were transfected with miR-708-5p mimics and miR-708-5p inhibitors, and expression levels of URGCP and NK- $\kappa \mathrm{B}$ were analyzed at the mRNA and protein levels. The results indicated that compared with the control group, miR-708-5p mimics and miR-708-5p inhibitors significantly decreased and increased the mRNA and protein levels of URGCP and NK- $\kappa$ B in SaOS-2 cells, respectively (Fig. 5C-I).

\section{Discussion}

Osteosarcoma is the most common primary malignant bone tumor with the highest incidence among individuals aged 10-20 years (2). However, the therapeutic effect of osteosarcoma is still unsatisfactory $(32,33)$. Therefore, identification of novel effective treatment methods for patients with osteosarcoma is required. miRNAs serve important roles in the occurrence and development of a number of diseases (34-36). Furthermore, previous studies indicated that miRNAs participate in the occurrence and development of osteosarcoma $(37,38)$. The role of miR-708-5p was previously studied in several types of cancer including cervical $(18,19)$, lung $(39)$ and prostate $(40)$ cancer. However, to the best of our knowledge, the role of miR-708-5p in osteosarcoma has not been previously studied.

The present study aimed to investigate the potential role of miR-708-5p in the development and progression of osteosarcoma in vitro, and that miR-708-5p may be a potential marker for the diagnosis of osteosarcoma. The present study detected the level of miR-708-5p in osteosarcoma tissues, adjacent normal tissues, human osteosarcoma cell line SaOS-2 and normal osteoblast hFOB1.19 cell line. miR-708-5p was significantly downregulated in osteosarcoma tissues and cells, indicating that miR-708-5p may be involved in the occurrence and development of this disease. The effects of miR-708-5p overexpression on SaOS-2 cells were studied using miR-708-5p mimics. Transfection with miR-708-5p mimics significantly inhibited cell growth, induced cell apoptosis, and inhibited cell invasion and migration in vitro. The present study also demonstrated that URGCP was a direct target of miR-708-5p.

URGCP is an oncogene that contributes to carcinogenesis, cell cycle regulation and cell proliferation in cells (41). URGCP is involved in the development of various types of cancer (42-44), and promotes the malignant behavior of cancer cells by regulating the $N F-\kappa B$ signaling pathway (45-47). In the present study, miR-708-5p overexpression inhibited the expression of URGCP and NF- $\kappa \mathrm{B}$ in SaOS-2 cells, while miR-708-5p downregulation enhanced the expression of URGCP and NF- $\mathrm{NB}$. The data indicated that miR-708-5p may inhibit osteosarcoma cell viability and invasion by regulating the $\mathrm{URGCP} / \mathrm{NF}-\kappa \mathrm{B}$ signaling pathway.

In conclusion, to the best of our knowledge, the present study is the first to indicate that miR-708-5p was significantly downregulated in osteosarcoma tissues and cells. miR-708-5p overexpression inhibited osteosarcoma cell viability, migration and invasion, and induced cell apoptosis. Furthermore, the results of the present study indicated that URGCP was a direct target gene of miR-708-5p. The current study provides novel insights into osteosarcoma research and targeted therapies. According to the present preliminary study, miR-708-5p may be a novel and promising therapeutic target for the treatment of osteosarcoma. However, the tumor suppressor role of miR-708-5p in osteosarcoma requires further investigation. Future studies should determine whether the overexpression of URGCP or NF-kB could reverse the effects of miR-708-5p on SaOS-2 cells. Furthermore, potential association between patient prognosis and miR-708-5p expression may be studied in the future.

\section{Acknowledgements}

Not applicable.

\section{Funding}

No funding was received.

\section{Availability of data and materials}

The datasets used and/or analyzed during the current study are available from the corresponding author on reasonable request.

\section{Authors' contributions}

CS and DL collaborated to design the study. CS, DL and YH were responsible for data access and analysis. $\mathrm{LZ}$ interpreted the results. All authors collaborated to develop the manuscript.

\section{Ethics approval and consent to participate}

All experiments involving human tissues were reviewed and approved by the Ethics Committee of the First Affiliated Hospital of Anhui Medical University and by the Ethics Committee of the First Affiliated Hospital of University of Science and Technology of China. All patients provided written informed consent for the use of their tissues.

\section{Patient consent for publication}

Not applicable.

\section{Competing interests}

The authors declare that they have no competing interests.

\section{References}

1. Li X, Lu Q, Xie W, Wang Y and Wang G: Anti-tumor effects of triptolide on angiogenesis and cell apoptosis in osteosarcoma cells by inducing autophagy via repressing Wnt $/ \beta$-Catenin signaling. Biochem Biophys Res Commun 496: 443-449, 2018.

2. Lo YC, Lin YC, Huang YF, Hsieh CP, Wu CC, Chang IL, Chen CL, Cheng $\mathrm{CH}$ and Chen HY: Carnosol-induced ROS inhibits cell viability of human osteosarcoma by apoptosis and autophagy. Am J Chin Med 45: 1761-1772, 2017.

3. Liu ZR, Sun LZ, Jia TH and Jia DF: $\beta$-Aescin shows potent antiproliferative activity in osteosarcoma cells by inducing autophagy, ROS generation and mitochondrial membrane potential loss. J BUON 22: 1582-1586, 2017. 
4. Xu HY, Fang W, Huang ZW, Lu JC, Wang YQ, Tang QL, Song GH, Kang Y, Zhu XJ, Zou CY, et al: Metformin reduces SATB2-mediated osteosarcoma stem cell-like phenotype and tumor growth via inhibition of N-cadherin/NF-kB signaling. Eur Rev Med Pharmacol Sci 21: 4516-4528, 2017.

5. Shaikh AB, Li F, Li M, He B, He X, Chen G, Guo B, Li D, Jiang F, Dang L, et al: Present advances and future perspectives of molecular targeted therapy for osteosarcoma. Int J Mol Sci 17: 506, 2016

6. Hu L, Ai J, Long H, Liu W, Wang X, Zuo Y, Li Y, Wu Q and Deng Y: Intergrative microRNA and gene profiling data analysis reveals novel biomarkers and mechanisms for lung cancer Oncotarget 7: 8441-8454, 2016.

7. Tsai MM, Wang CS, Tsai CY, Huang HW, Chi HC, Lin YH, $\mathrm{Lu} \mathrm{PH}$ and Lin KH: Potential diagnostic, prognostic and therapeutic targets of microRNAs in human gastric cancer. Int J Mol Sci 17: E945, 2016.

8. Zhao H, Li M, Li L, Yang X, Lan G and Zhang Y: MiR-133b is down-regulated in human osteosarcoma and inhibits osteosarcoma cells proliferation, migration and invasion, and promotes apoptosis. PLoS One 8: e83571, 2013.

9. Kaukoniemi KM, Rauhala HE, Scaravilli M, Latonen L, Annala M, Vessella RL, Nykter M, Tammela TL and Visakorpi T: Epigenetically altered miR-193b targets cyclin D1 in prostate cancer. Cancer Med 4: 1417-1425, 2015.

10. Zimmerman AL and Wu S: MicroRNAs, cancer and cancer stem cells. Cancer Lett 300: 10-19, 2011.

11. Schwarzenbacher D, Balic $M$ and Pichler $M$ : The role of microRNAs in breast cancer stem cells. Int J Mol Sci 14 14712-14723, 2013.

12. Bartel DP: MicroRNAs: Target recognition and regulatory functions. Cell 136: 215-233, 2009.

13. Friedman JM and Jones PA: MicroRNAs: Critical mediators of differentiation, development and disease. Swiss Med Wkly 139: 466-472, 2009

14. Schneider MR: MicroRNAs as novel players in skin development, homeostasis and disease. Br J Dermatol 166: 22-28, 2012.

15. Coghlin C and Murray GI: Current and emerging concepts in tumour metastasis. J Pathol 222: 1-15, 2010

16. Zhang Y, Kim J, Mueller AC, Dey B, Yang Y, Lee DH, Hachmann J, Finderle S, Park DM, Christensen J, et al: Multiple receptor tyrosine kinases converge on microRNA-134 to control KRAS, STAT5B, and glioblastoma. Cell Death Differ 21 720-734, 2014.

17. Garg M: Emerging role of microRNAs in cancer stem cells: Implications in cancer therapy. World J Stem Cells 7: 1078-1089, 2015.

18. Kloosterman WP and Plasterk RH: The diverse functions of microRNAs in animal development and disease. Dev Cell 11: 441-450, 2006

19. Bicker S and Schratt G: microRNAs: Tiny regulators of synapse function in development and disease. J Cell Mol Med 12: 1466-1476, 2008

20. Condorelli G and Dimmeler S: MicroRNAs: Components of an integrated system controlling cardiac development, physiology, and disease pathogenesis. Cardiovasc Res 79: 551-552, 2008

21. He X, Eberhart JK and Postlethwait JH: MicroRNAs and micromanaging the skeleton in disease, development and evolution. J Cell Mol Med 13: 606-618, 2009.

22. Chhabra R and Saini N: MicroRNAs in cancer stem cells: Current status and future directions. Tumour Biol 35: 8395-8405, 2014

23. Liu M, Lu S, He W, Zhang L, Ma Y, Lv P, Ma M, Yu W, Wang J, Zhang M, et al: ULK1-regulated autophagy: A mechanism in cellular protection for ALDH2 against hyperglycemia. Toxico Lett 283: 106-115, 2018

24. Ji Q, Karnak D, Hao P, Wang R and Xu L: No small matter: MicroRNAs - key regulators of cancer stem cells. Int J Clin Exp Med 3: 84-87, 2010.

25. Nimmo RA and Slack FJ: An elegant miRror: MicroRNAs in stem cells, developmental timing and cancer. Chromosoma 118 405-418, 2009

26. Meng F, Glaser SS, Francis H, DeMorrow S, Han Y, Passarini JD, Stokes A, Cleary JP, Liu X, Venter J, et al: Functional analysis of microRNAs in human hepatocellular cancer stem cells. J Cell Mol Med 16: 160-173, 2012.

27. Xia H and Hui KM: MicroRNAs involved in regulating epithelial-mesenchymal transition and cancer stem cells as molecular targets for cancer therapeutics. Cancer Gene Ther 19: 723-730, 2012 .
28. Shen Y, Pan Y, Xu L, Chen L, Liu L, Chen H, Chen Z and Meng Z: Identifying microRNA-mRNA regulatory network in gemcitabine-resistant cells derived from human pancreatic cancer cells. Tumour Biol 36: 4525-4534, 2015.

29. Huang YH, Yang YL, Huang FC, Tiao MM, Lin YC, Tsai MH and Wang FS: MicroRNA-29a mitigation of endoplasmic reticulum and autophagy aberrance counteracts in obstructive jaundice-induced fibrosis in mice. Exp Boil Med (Maywood) 243 $13-21,2018$

30. Tian J, An X and Niu L: Role of microRNAs in cardiac development and disease. Exp Ther Med 13: 3-8, 2017.

31. Livak KJ and Schmittgen TD: Analysis of relative gene expression data using real-time quantitative PCR and the 2(-Delta Delta C(T)) method. Methods 25: 402-408, 2001

32. Yang J and Zhang W: New molecular insights into osteosarcoma targeted therapy. Curr Opin Oncol 25: 398-406, 2013.

33. Tsuchiya H, Tomita K, Mori Y, Asada N, Morinaga T, Kitano S and Yamamoto N: Caffeine-assisted chemotherapy and minimized tumor excision for nonmetastatic osteosarcoma. Anticancer Res 18: 657-666, 1998.

34. Croce CM: Causes and consequences of microRNA dysregulation in cancer. Nat Rev Genet 10: 704-714, 2009.

35. Magri F, Vanoli F and Corti S: miRNA in spinal muscular atrophy pathogenesis and therapy. J Cell Mol Med 22: 755-767, 2018.

36. Romakina VV, Zhirov IV, Nasonova SN, Zaseeva AV, Kochetov AG, Liang OV and Tereshchenko SN: MicroRNAs as biomarkers of cardiovascular diseases. Kardiologiia: 66-71, 2018 (In Russian).

37. Tian K, Wang L, Di R, Xu J, Li G and Li Z: Effect and mechanism of miRNA to osteosarcoma cell. Pak J Pharm Sci 27(5 Suppl): 1657-1660, 2014

38. Xie B, Li Y, Zhao R, Xu Y, Wu Y, Wang J, Xia D, Han W and Chen D: Identification of key genes and miRNAs in osteosarcoma patients with chemoresistance by bioinformatics analysis. Biomed Res Int 2018: 4761064, 2018.

39. Wu X, Liu T, Fang O, Dong W, Zhang F, Leach L, Hu X and Luo Z: MicroRNA-708-5p acts as a therapeutic agent against metastatic lung cancer. Oncotarget 7: 2417-2432, 2016.

40. Yang J, Wei J, Wu Y, Wang Z, Guo Y, Lee P and Li X: Metformin induces ER stress-dependent apoptosis through miR-708-5p/NNAT pathway in prostate cancer. Oncogenesis 4: e158, 2015.

41. Dodurga Y, Seçme M and Lale Şatıroğlu-Tufan N: A novel oncogene URG4/URGCP and its role in cancer. Gene 668: 12-17, 2018.

42. Yu G, Zhang T, Jing Y, Bao Q, Tang Q and Zhang Y: miR-519 suppresses nasopharyngeal carcinoma cell proliferation by targeting oncogene URG4/URGCP. Life Sci 175: 47-51, 2017.

43. Tokay E and Kockar F: Identification of intracellular pathways through which TGF- $\beta 1$ upregulates URG-4/URGCP gene expression in hepatoma cells. Life Sci 144: 121-128, 2016.

44. Dodurga Y, Seçme M, Eroğlu C, Gündoğdu G, Avcı CB, Bağcı G, Küçükatay V and Lale Şatıroğlu-Tufan N: Investigation of the effects of a sulfite molecule on human neuroblastoma cells via a novel oncogene URG4/URGCP. Life Sci 143: 27-34, 2015.

45. Cai J, Li R, Xu X, Zhang L, Wu S, Yang T, Fang L, Wu J, Zhu X, Li M and Huang Y: URGCP promotes non-small cell lung cancer invasiveness by activating the NF- $\mathrm{BB}-\mathrm{MMP}-9$ pathway. Oncotarget 6: 36489-36504, 2015.

46. Wu M, Chen J, Wang Y, Hu J, Liu C, Feng C and Zeng X: URGCP/URG4 promotes apoptotic resistance in bladder cancer cells by activating NF- $\kappa \mathrm{B}$ signaling. Oncotarget 6: 30887-30901, 2015.

47. Xing S, Zhang B, Hua R, Tai WC, Zeng Z, Xie B, Huang C, Xue J, Xiong S, Yang J, et al: URG4/URGCP enhances the angiogenic capacity of human hepatocellular carcinoma cells in vitro via activation of the NF- $\kappa \mathrm{B}$ signaling pathway. BMC Cancer 15: 368 , 2015.

This work is licensed under a Creative Commons Attribution-NonCommercial-NoDerivatives 4.0 International (CC BY-NC-ND 4.0) License. 